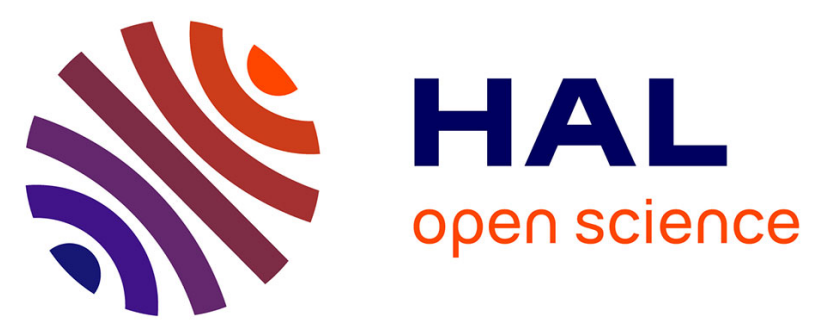

\title{
A Kelvin probe force microscopy study of hydrogen insertion and desorption into 2024 aluminum alloy
}

Manon Chloé Lafouresse, Marie-Laëtitia De Bonfils - Lahovary, Cédric Charvillat, Loïc Oger, Lydia Laffont-Dantras, Christine Blanc

\section{- To cite this version:}

Manon Chloé Lafouresse, Marie-Laëtitia De Bonfils - Lahovary, Cédric Charvillat, Loïc Oger, Lydia Laffont-Dantras, et al.. A Kelvin probe force microscopy study of hydrogen insertion and desorption into 2024 aluminum alloy. Journal of Alloys and Compounds, 2017, vol. 722, pp. 760-766. 10.1016/j.jallcom.2017.06.143 . hal-01627635

\section{HAL Id: hal-01627635 \\ https://hal.science/hal-01627635}

Submitted on 21 Nov 2017

HAL is a multi-disciplinary open access archive for the deposit and dissemination of scientific research documents, whether they are published or not. The documents may come from teaching and research institutions in France or abroad, or from public or private research centers.
L'archive ouverte pluridisciplinaire HAL, est destinée au dépôt et à la diffusion de documents scientifiques de niveau recherche, publiés ou non, émanant des établissements d'enseignement et de recherche français ou étrangers, des laboratoires publics ou privés. 


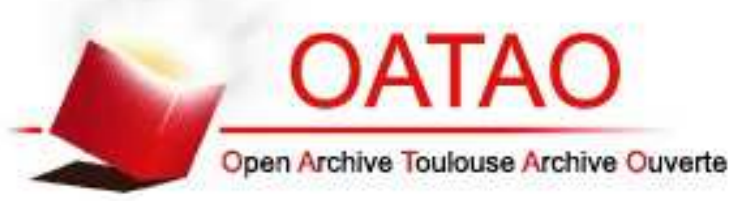

\section{Open Archive TOULOUSE Archive Ouverte (OATAO)}

OATAO is an open access repository that collects the work of Toulouse researchers and makes it freely available over the web where possible.

This is an author-deposited version published in : http://oatao.univ-toulouse.fr/ Eprints ID : 18123

To link to this article : DOI: $10.1016 /$ j.jallcom.2017.06.143

URL : http://dx.doi.org/10.1016/j.jallcom.2017.06.143

To cite this version : Lafouresse, Manon Chloé and Bonfils -

Lahovary, Marie-Laëtitia de and Charvillat, Cédric and Oger, Loïc and Laffont-Dantras, Lydia and Blanc, Christine A Kelvin probe force microscopy study of hydrogen insertion and desorption into 2024 aluminum alloy. (2017) Journal of Alloys and Compounds, vol. 722. pp. 760-766. ISSN 0925-8388

Any correspondence concerning this service should be sent to the repository administrator: staff-oatao@ listes-diff.inp-toulouse.fr 


\title{
A Kelvin probe force microscopy study of hydrogen insertion and desorption into 2024 aluminum alloy
}

\author{
Manon Chloé Lafouresse, Marie-Laëtitia de Bonfils-Lahovary, Cédric Charvillat, Loïc Oger, \\ Lydia Laffont, Christine Blanc*
}

CIRIMAT, Université de Toulouse, CNRS, INPT, UPS, ENSIACET, 4 allée Emile Monso, CS44362, 31030, Toulouse, France

\begin{abstract}
A B S T R A C T
Hydrogen was inserted into 2024 aluminum alloy by cathodic polarization in sulfuric acid at $25^{\circ} \mathrm{C}$. Scanning Kelvin Probe Force Microscopy (SKPFM) measurements performed perpendicularly to the charging side revealed a potential gradient and confirmed the insertion of hydrogen over hundreds of microns. A hydrogen diffusion coefficient of $1.7 \times 10^{-9} \mathrm{~cm}^{2} \mathrm{~s}^{-1}$ was calculated from SKPFM measurements of H-charged samples for different durations. The evolution of the potential gradient during desorption of hydrogen in air, at room temperature and at $130{ }^{\circ} \mathrm{C}$ was investigated. Additional experiments performed at a corrosion defect showed that SKPFM could detect both reversibly and irreversibly bounded hydrogen. These results show that SKPFM is a cutting-edge technique for hydrogen detection and localization at a local scale.
\end{abstract}

Keywords:

Hydrogen absorption

Hydrogen desorption

Atomic Force Microscopy (AFM)

Scanning Kelvin Probe Force Microscopy

(SKPFM)

\section{Introduction}

Hydrogen, which is a by-product of corrosion reactions, is suspected to play a major role in the loss of mechanical properties of aluminum alloys and more particularly to be responsible for their embrittlement and fracture [1]. It can be both inserted into the lattice (interstitial hydrogen) and irreversibly at microstructural defects (e.g. grain boundaries or vacancies) or precipitates. Interstitial hydrogen desorbs at room temperature while for hydrogen trapped at other locations, critical desorption temperatures have to be reached for it to desorb [2]. Moreover hydrogen trapped at different microstructural locations can play different roles in the degradation of the material. It is therefore essential to detect and localize hydrogen at least at the micrometer scale to better understand the influence of hydrogen and of its location on the material embrittlement.

It is however difficult to detect and localize hydrogen at the scale of the corrosion defects which requires the use of analytical techniques with very high lateral resolution. Previous works proposed the development of analytical techniques to detect hydrogen

\footnotetext{
* Corresponding author

E-mail address: christine.blanc@ensiacet.fr (C. Blanc).
}

in cathodically charged samples. In that way, a powerful way to study hydrogen embrittlement is by using Atomic Force Microscope (AFM) based Scanning Kelvin Probe Force Microscopy (SKPFM). By measuring the surface potential at the nanometer scale, this technique allows the detection and localization of hydrogen in the alloy through a change in the work function caused by the hydrogenation. Some authors have detected hydrogen in metals or alloys at the local scale with SKPFM [3-5]. Larignon et al. showed that hydrogen could be detected in cathodically H-charged 2024 aluminum alloy (AA 2024) as well as at grain and subgrain boundaries by SKPFM [6,7]. In this work, the AA 2024 was Hcharged in molten salts at $150{ }^{\circ} \mathrm{C}$ and a gradient in potential associated with the presence of hydrogen was measured by SKPFM. Then, it seems relevant to study whether hydrogen can be detected by SKPFM at the scale of the corrosion defects. Further, it is of great interest to study hydrogen desorption in order to have a better understanding of the hydrogen trapping phenomena.

In the present work, hydrogen diffusion profiles were taken by SKPFM over a few hundreds of microns for AA 2024 samples hydrogen charged cathodically in acidic solution at $25^{\circ} \mathrm{C}$. In addition, the evolution of the profiles with exposure to air at room temperature as well as at a higher temperature was followed to obtain information about hydrogen desorption. SKPFM analysis was also performed at a corrosion defect for an AA 2024 sample 
after immersion in $1 \mathrm{M} \mathrm{NaCl}$ and after heat treatment at different temperatures in order to distinguish between hydrogen trapped at different locations.

\section{Materials and methods}

The material used was an AA 2024-T351 rolled plate with the following chemical composition (in wt. \%): $4.46 \% \mathrm{Cu}, 1.44 \% \mathrm{Mg}$, $0.60 \% \mathrm{Mn}$ and $0.13 \% \mathrm{Fe}[8]$. Hydrogen was inserted into the AA 2024 by cathodic charging at $25{ }^{\circ} \mathrm{C}$ in $10 \mathrm{mM} \mathrm{H}_{2} \mathrm{SO}_{4}$ ( $\geq 95 \%$ Sigma Aldrich). Electrochemical cathodic charging in acidic solution was selected as large quantities of hydrogen $(>1000 \mathrm{appm})$ could be inserted with this method into pure aluminum [9]. A Pt counter electrode and a saturated calomel reference electrode (SCE) were used. The charging potential, $E$, was $-0.8 \mathrm{~V}$ vs SCE and the charging

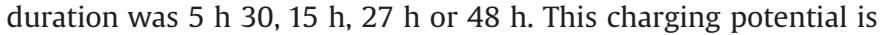
situated at the transition zone between the oxygen reduction reaction and the hydrogen reduction reaction as shown in the polarization curve for AA 2024 in $10 \mathrm{mM} \mathrm{H}_{2} \mathrm{SO}_{4}$ (Fig. 1(a)). In Fig. 1(b), the charging curve for AA 2024 is displayed. It takes a couple of hours for the current density value to reach its plateau value. This is probably due to the oxygen reaction in the first hours being progressively replaced by the hydrogen reduction reaction. The progressive apparition of bubbles on the surface seems to agree with this hypothesis. The charging side was chosen to be perpendicular to the elongated grain direction (rolling direction, RD) [8]. Therefore, one of the long transverse (LT) - short transverse (ST) sides of the parallelepiped sample $\left(\sim 2 \times 2 \times 20 \mathrm{~mm}^{3}(\mathrm{LT} \times \mathrm{RD} \times \mathrm{ST})\right)$ was exposed to the electrolyte while all the other sides were protected by silicone elastomer paste (Fig. 2(a)). Before charging, the charging side was polished with diamond paste down to $3 \mu \mathrm{m}$. Following the charging, the ST- RD side was polished down to $0.25 \mu \mathrm{m}$ with diamond paste and with distilled water as a lubricant, thoroughly rinsed with distilled water and then imaged by SKPFM. A minimum of $300 \mu \mathrm{m}$ was removed by polishing in the LT direction to avoid edge effects. Some samples were stored in liquid nitrogen for gas fusion analysis.

For preparing corroded 2024 aluminum alloy samples, a continuous immersion of the alloy in $1 \mathrm{M} \mathrm{NaCl}$ at $25^{\circ} \mathrm{C}$ for $24 \mathrm{~h}$ was performed. A cubic sample of about $1 \times 1 \times 1 \mathrm{~mm}^{3}$ was prepared and one of the LT-ST sides was exposed to the $\mathrm{NaCl}$ solution after polishing down to $3 \mu \mathrm{m}$ (Fig. 2(b)). All the other sides were protected with varnish. Following the immersion, the sample was rinsed with water, dried and cut in two along the ST-RD plane. The ST-RD side was then polished with down to $0.25 \mu \mathrm{m}$ diamond paste and imaged in SKPFM.

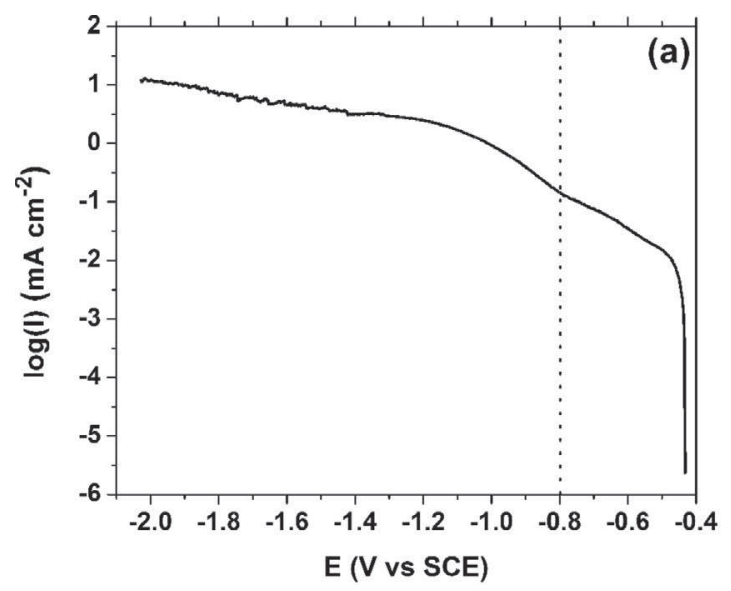

Heat treatments for hydrogen desorption were performed in a Carbolite furnace.

The hydrogen content of the cathodically charged samples was determined by gas fusion analysis using a Bruker G8 GALILEO ON/H Instrumental Gas Analyser (IGA). The sample is melted in a graphite crucible at high temperature and the hydrogen content is then measured by thermal conductivity measurements of the gas. Parallelepiped samples of mass $(130 \pm 5) \mathrm{mg}$ and of dimensions $\sim 3.2 \times 1.1 \times 14.5 \mathrm{~mm}^{3}(\mathrm{LT} \times \mathrm{RD} \times \mathrm{ST})$ were prepared. The low sample thickness in the RD direction ensured that the noncharged part is kept to a minimum. Prior to the analysis, the sample was slightly polished with grade $1200 \mathrm{SiC}$ paper. This step is crucial in order to get accurate hydrogen content values, as demonstrated by Buckley et al. [10]. The authors showed that during cathodic charging, an $\mathrm{Al}(\mathrm{OH})_{3}$ layer forms on the aluminum sample surface. If not removed, erroneously high values of hydrogen were measured due to the decomposition of this $\mathrm{Al}(\mathrm{OH})_{3}$ layer into $\mathrm{Al}_{2} \mathrm{O}_{3}$ and $\mathrm{H}_{2}$.

The SKPFM measurements were performed on a 5500 Agilent AFM. Both topography and surface potential signals were acquired simultaneously (single pass mode). The probes were conductive Ptcoated silicon tips. In the single pass mode set up, the tip is vibrated above the surface at two different frequencies: a frequency close to the resonant frequency of the tip $(300 \mathrm{kHz})$ by mechanical excitation in order to control the tip-sample distance and a lower frequency $(10 \mathrm{kHz})$ by electrical excitation to measure the surface potential [11]. Amplitude modulation (AM) - KFM mode was used. In this mode, a voltage $V_{d c}+V_{a c} \sin (\omega t)$ is applied to the tip. The resulting oscillating potential difference between the tip and sample modulates the electrostatic force between the tip and the sample inducing an oscillation of the tip. $V_{d c}$ is adjusted, until the amplitude of the oscillations is minimal, which occurs when $V_{d c}$ is equal to the potential difference between the tip and the sample. This set up allows a high spatial resolution. All SKPFM measurements were performed in air at room temperature.

Concerning cathodically charged samples, to overcome the limited scan range $(90 \mu \mathrm{m})$ of the instrument, sequential images were taken so that cross sections of the sample over hundreds of microns could be acquired (Fig. 3). The first image was taken by starting from the edge adjacent to the charging side and scanning an $85 \mu \mathrm{m} \times 6 \mu \mathrm{m}$ area. The sample was then moved by about $50 \mu \mathrm{m}$ with micrometer screws in the direction perpendicular to the charging side and a second image was taken. An overlap of the potential value of the two adjacent images ensured that the surface potential value was stable. This procedure was repeated over up to a total length of about $600 \mu \mathrm{m}$.

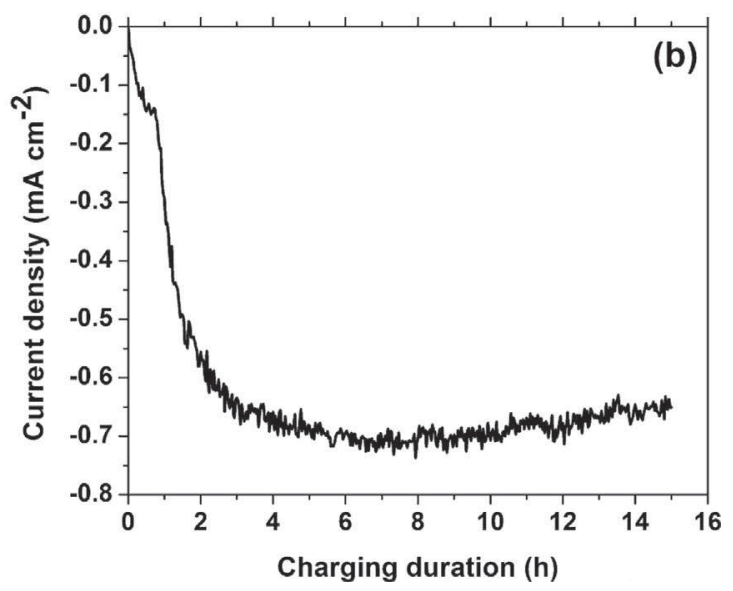

Fig. 1. (a) Polarization curve for $\mathrm{AA} 2024$ in $10 \mathrm{mM} \mathrm{H}_{2} \mathrm{SO}_{4}$ at $25{ }^{\circ} \mathrm{C}$. Scan rate $=1 \mathrm{~V} \mathrm{~h}^{-1}$. (b) Charging curve at $\mathrm{E}=-0.8 \mathrm{~V} / \mathrm{SCE}$. 
(a)

1. $\mathrm{H}$ charging in $10 \mathrm{mM} \mathrm{H}_{2} \mathrm{SO}_{4}$

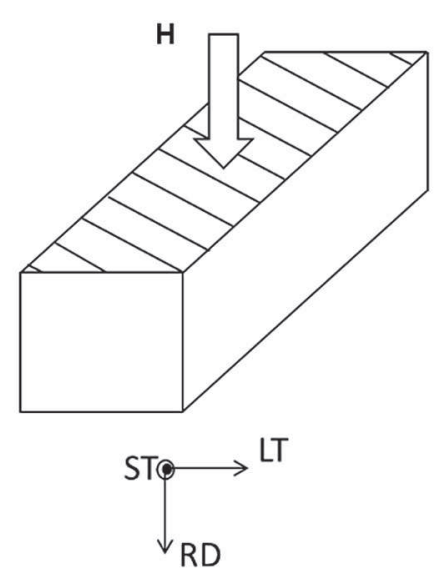

(b)

1. $\mathrm{H}$ charging in $1 \mathrm{M} \mathrm{NaCl}$

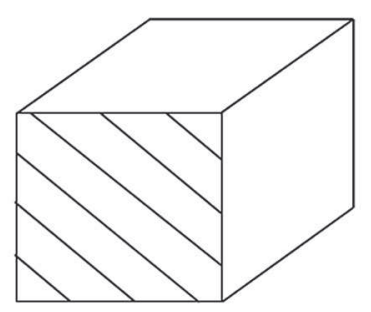

$\stackrel{\mathrm{RD}_{\mathrm{ST}}}{\stackrel{\mathrm{LT}}{\longrightarrow}}$

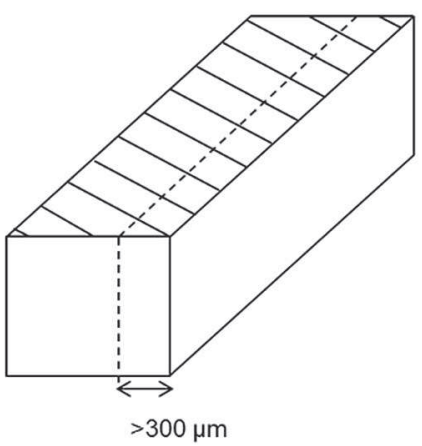

2. Cutting and polishing

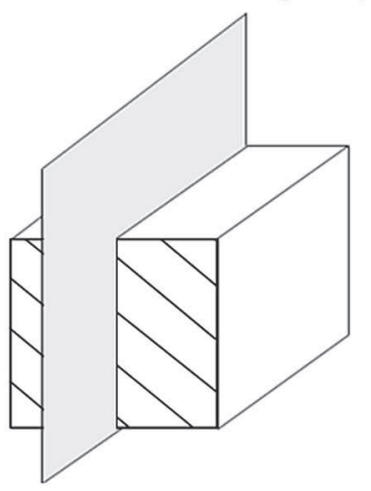

3. SKPFM analysis

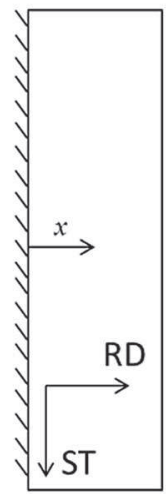

3. SKPFM analysis

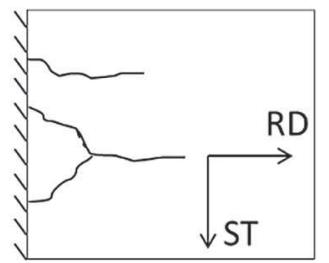

Fig. 2. Experimental procedures for preparation for SKPFM imaging of (a) an AA 2024 sample H-charged in $10 \mathrm{mM} \mathrm{H}_{2} \mathrm{SO}_{4}$ and (b) an $\mathrm{AA} 2024$ sample exposed to a $1 \mathrm{M}$ NaCl solution. The hatched zone represents the side exposed to the solution.

\section{Results and discussion}

\subsection{Hydrogen insertion during cathodic charging}

The potential profiles of an uncharged AA 2024 sample and a $15 \mathrm{~h} \mathrm{H}$-charged AA 2024 sample are shown in Fig. 4. All measurements are plotted with respect to a reference value of the potential. This reference value is the potential measured far away from the charging side, i.e. in the uncharged part of the sample. This value has been chosen as the SKPFM potential value in the uncharged part does vary from sample to sample due to small differences in temperature and relative humidity in the laboratory room. Therefore, for an accurate comparison between the samples, the potential plotted in Fig. 4 is the difference between the potential in the uncharged part of the sample, $V_{\infty}$, and the measured potential at a distance $x, V_{x}$. It is called $\Delta V$.

$\Delta V$ for the uncharged sample is constant over several hundreds of microns. On the contrary, the potential profile of the charged sample clearly follows a gradient with a lower value of $\Delta V$ close to the charging side as compared with the bulk. The potential gradient is observed over about $200 \mu \mathrm{m}$ and the maximum difference in potential value, $\Delta V_{\max }$, is $\sim 350 \mathrm{mV}$. Similar SKPFM potential gradients have been observed by Larignon et al. for AA 2024 also charged in hydrogen but with a different method and at a higher temperature [6]. In Larignon's work, secondary ion mass spectroscopy (SIMS) measurements were performed in parallel and showed the presence of a gradient of hydrogen over distances

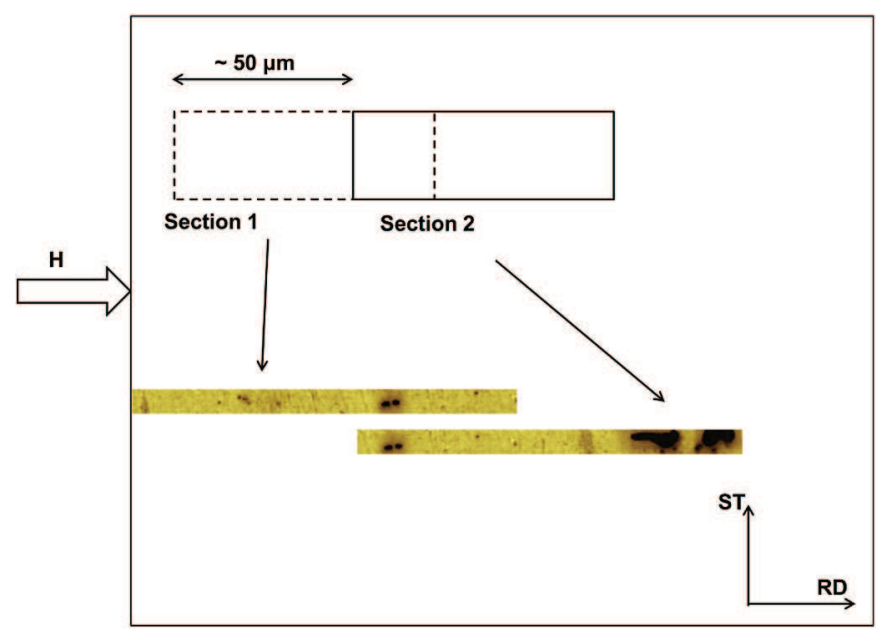

Fig. 3. Schematic of the overlapping section method used during the SKPFM measurements. The first two SKPFM potential images are shown to demonstrate the overlapping. 


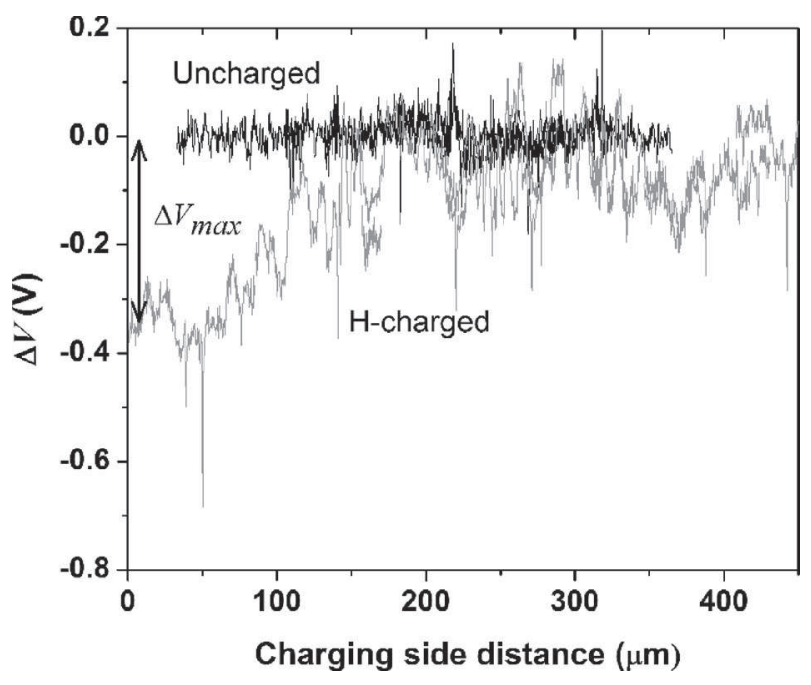

Fig. 4. SKPFM potential difference $\Delta V=V_{\infty}-V_{x}$ as a function of the distance $x$ from the H-charging side for uncharged (black) and $15 \mathrm{~h} \mathrm{H}$-charged (grey) AA 2024 samples. $V_{\infty}$ is the potential measured in the H-free sample, far away from the charging surface.

similar to the ones found for the SKPFM potential gradient. These gradients in potential were therefore linked with a gradient in hydrogen in the material. In the present study, the hydrogen presence in the sample was confirmed by gas fusion analysis. An average of $14 \mathrm{ppm}$ was measured for a charging duration of $15 \mathrm{~h}$. As a reference, the uncharged AA 2024 contains 7 ppm of residual hydrogen.

Therefore, the comparison between the potential profiles of a $\mathrm{H}-$ charged and an uncharged AA 2024 samples and the confirmation of additional hydrogen inserted during cathodic charging by IGA measurements indicate that hydrogen can be detected with SKPFM and its penetration depth in the material measured.

The evolution of the surface potential difference gradient as a function of charging duration was also studied. Both the diffusion depth of hydrogen and the maximum difference in potential value $\left(\Delta V_{\max }\right)$ extracted from the potential profiles (not shown) are presented in Fig. 5. The diffusion depth was measured at the point where the difference in potential reaches zero. There is, as expected, a clear increase of both the penetration depth and $\Delta V_{\max }$ value as the charging duration is increased.

Hydrogen diffusion profiles can be calculated from the analytical

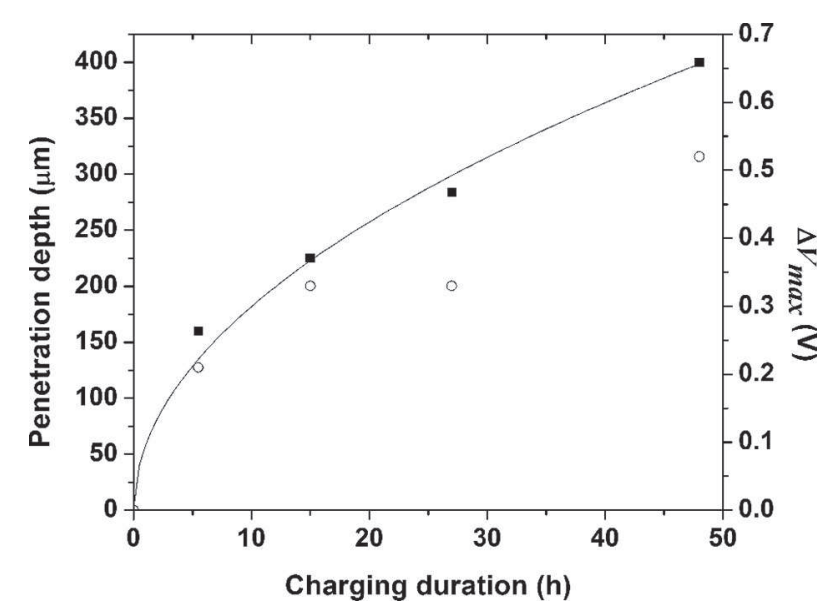

Fig. 5. Penetration depth ( $\square)$ and maximum potential difference $(O)$ for a range of charging durations. The solid line represents the results of a fit to Eq. (3). solution to Fick's second law [12]. For the following boundary conditions

$c(x>0, t=0)=c_{0}$

$c(x=0, t)=c_{S}$

where $c_{0}$ is the initial hydrogen concentration in the bulk material at a distance $x>0$ from the surface and at a time $t=0$ and $c_{s}$ is the surface concentration at a time $t$, then [12]

$\frac{c(x, t)-c_{s}}{c_{0}-c_{s}}=\operatorname{erf}\left(\frac{x}{2 \sqrt{D t}}\right)$

where $c(x, t)$ is the hydrogen concentration at a distance $x$ from the surface and at a charging time $t$ and $D$ is the hydrogen diffusion coefficient. $c_{o}$ and $c_{S}$ were assumed to be equal to 0 and 1 , respectively.

Eq. (2) can be rearranged as follows

$$
\left.x \approx 2 \sqrt{D}\left(\frac{-\ln (c(x, t))}{1.9}\right)^{\frac{1}{1.3}}\right) \times \sqrt{t}
$$

The solid line in Fig. 5 represents the results of a fit to Eq. (3). A good agreement between theoretical hydrogen diffusion calculations and experimental hydrogen diffusion measurements is observed. Moreover the diffusion coefficient value, $D$, can be extracted from the fit of the potential profile curves (not shown). $D$ was measured to be equal to $(1.7 \pm 0.9) \times 10^{-9} \mathrm{~cm}^{2} \mathrm{~s}^{-1}$, which is close to the value of $10^{-9} \mathrm{~cm}^{2} \mathrm{~s}^{-1}$ calculated for AA 2024 at $25^{\circ} \mathrm{C}$ from thermal desorption experiments [1]. Larignon et al. found a value of $1-14 \times 10^{-9} \mathrm{~cm}^{2} \mathrm{~s}^{-1}$ based on SIMS measurements and $(7 \pm 2) \times 10^{-9} \mathrm{~cm}^{2} \mathrm{~s}^{-1}$ based on open circuit potential (OCP) and SKPFM measurements [6]. These slightly higher values can be explained by the fact that charging was done at a higher temperature $\left(150^{\circ} \mathrm{C}\right)$. These SKPFM measurements give only access to the penetration depth, not to the quantity of hydrogen being inserted. So, in addition, hydrogen content for different charging durations was determined by gas fusion method. As the hydrogen penetration depth is no more than $400 \mu \mathrm{m}$, samples $\sim 1.1 \mathrm{~mm}$ thick were prepared to ensure than the non-charged zone is as small as possible not to give erroneously low $\mathrm{H}$ content values. However, the error remains significant and only approximate values can be given: the interest is in the comparison of the different values. As previously given, for the uncharged alloy a value of $7 \mathrm{ppm}$ was measured due to hydrogen inserted during elaboration processing. For the $5 \mathrm{~h} 30$, $15 \mathrm{~h}, 27 \mathrm{~h}$ and $48 \mathrm{~h}$, the $\mathrm{H}$ content measured was $12 \mathrm{ppm}, 14 \mathrm{ppm}, 15$ and $17 \mathrm{ppm}$ respectively. Therefore an increase in the hydrogen content with the charging duration is indeed measured, in agreement with the SKPFM results. The good agreement between the theory for $\mathrm{H}$ diffusion and the measured potential gradients as well as the IGA measurements confirms that the potential gradients are due to the presence of hydrogen. Moreover the method of inserting hydrogen into the aluminum alloy at a low temperature developed here rules out possible microstructural modifications of the alloy by artificial ageing.

\subsection{Hydrogen desorption for cathodically H-charged AA 2024 sample}

SKPFM has also been used to study the desorption of hydrogen from a pre-charged AA 2024 sample. The sample was charged for $15 \mathrm{~h}$ at $-0.8 \mathrm{~V}$ in $10 \mathrm{mM} \mathrm{H}_{2} \mathrm{SO}_{4}$. The gradient in potential of the ascharged sample is displayed in Fig. 6(a). In this figure, $\Delta V$ has been 
averaged every $30 \mu \mathrm{m}$ for clarity. A gradient over about $250 \mu \mathrm{m}$ associated with a $\Delta V_{\max }$ of $300 \mathrm{mV}$ was measured, as expected for this charging duration (Fig. 5). The sample was then exposed to air at room temperature and the potential gradient was measured again after $24 \mathrm{~h}$ and $48 \mathrm{~h}$. The ST-RD side was polished before each measurement. The gradients are presented in Fig. 6(a). After $24 \mathrm{~h}$, the gradient extents only over the first $100 \mu \mathrm{m}$ and $\Delta V_{\max }$ has decreased. After $48 \mathrm{~h}$, there is no more gradient, suggesting that the majority of the detected $\mathrm{H}$ has desorbed. Fig. 6(b) confirms the complete desorption of $\mathrm{H}$ at relatively low temperature. Indeed, in this figure, the potential gradient displayed by a pre-charged $\mathrm{H}$ sample has disappeared after a $2 \mathrm{~h}$ heat treatment at $130^{\circ} \mathrm{C}$. To rule out errors due to the influence of the heat treatment at $130{ }^{\circ} \mathrm{C}$ on the SKPFM response of the alloy, the potential gradient of an uncharged sample heat treated at $130{ }^{\circ} \mathrm{C}$ was recorded. As shown in Fig. 6(b) the gradient of the uncharged sample was not affected by the heat treatment at $130^{\circ} \mathrm{C}$. It is also important to note the good reproducibility for samples charged for $15 \mathrm{~h}$ (Figs. 4 and 6(a), (b)).

In this study, hydrogen was found to desorb at $130{ }^{\circ} \mathrm{C}$ and even at room temperature. At this temperature, only interstitial hydrogen is expected to desorb. Thermal desorption analysis of AA 2024 exposed to accelerated corrosion tests in exfoliation corrosion (EXCO) solution revealed the presence of four trapping states (T1-T4) for hydrogen [2]. T1 is a reversible trap i.e. hydrogen trapped in $\mathrm{T} 1$ can desorb at room temperature. T2, T3 and T4 are irreversible traps i.e. a critical temperature has to be reached in order for $\mathrm{H}$ to desorb from these traps $\left(200{ }^{\circ} \mathrm{C}, 410{ }^{\circ} \mathrm{C}\right.$ and $500{ }^{\circ} \mathrm{C}$ respectively). T1 was associated with hydrogen at interstitial sites, $\mathrm{T} 2$ at the interface between some intermetallic particles and the matrix, $\mathrm{T} 3$ at dislocations, $\mathrm{T} 4$ at the $\mathrm{S}$-phase particles $\left(\mathrm{Al}_{2} \mathrm{CuMg}\right)$ $[1,2,13]$. In the present paper, most of the hydrogen detected by SKPFM has desorbed at room temperature after $48 \mathrm{~h}$ or after heat treatment for $2 \mathrm{~h}$ at $130^{\circ} \mathrm{C}$. Therefore most of the hydrogen being detected is assumed to be interstitial hydrogen. This result does not rule out the presence of irreversibly trapped hydrogen in the cathodically charged sample. During cathodic charging case, the hydrogen does not necessarily go to the same traps as in the EXCO experiment. Indeed, in EXCO experiment the hydrogen is produced at the grain boundary, but not in hydrogen charging method. Furthermore the interstitial hydrogen introduced during cathodic charging might have diffused to very localized microstructural traps which were not captured on the cross sections imaged. To further check the capability of SKPFM to detect hydrogen trapped at irreversible trapping sites, SKPFM was then performed on corroded samples.

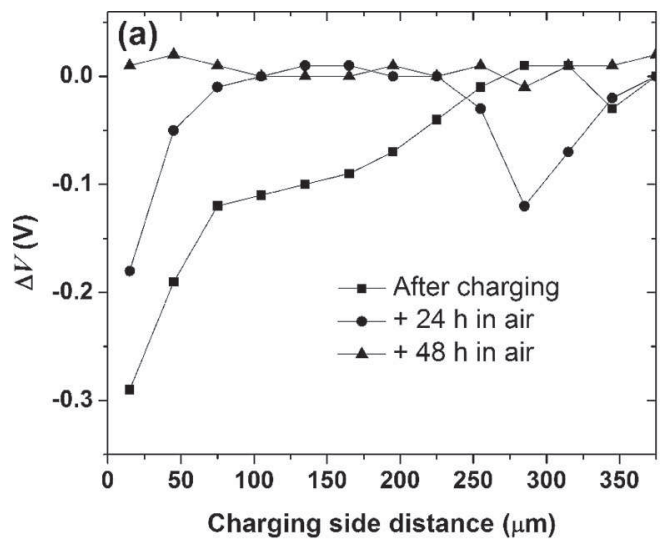

\subsection{H desorption at corrosion defects}

In Fig. 7, the potential map measured by SKPFM taken at a corrosion defect is shown. The images are flattened so that $\Delta V$ corresponds to the difference between the potential in the matrix and the measured potential at position $(x, y)$. The potential map after immersion in $1 \mathrm{M} \mathrm{NaCl}$ for $24 \mathrm{~h}$ is presented in Fig. 7(a). A corrosion defect is clearly visible in the potential image (Fig. 7(a)). Indeed a zone of lower $\Delta V$ is observed which was found to coincide with a defect spotted with the optical microscope. As AA 2024 is affected by intergranular corrosion, it is concluded that these defects are the consequence of corrosion along grain boundaries. The decrease in $\Delta V$ is observed over a $\sim 1.5$ to $2 \mu \mathrm{m}$ wide zone with a $\Delta V_{\text {max }}$ of $550 \mathrm{mV}$ (Fig. 7(e) and (f)). Note that the defect is more visible on the $\Delta V$ image than on the topographic image as already observed in a previous study [14]. The same zone was then imaged in SKPFM after heat treatment of the sample at $130^{\circ} \mathrm{C}, 200^{\circ} \mathrm{C}$ and $410^{\circ} \mathrm{C}$ for $2 \mathrm{~h}$ as shown in Fig. 7(b), (c) and (d) respectively. These temperatures were chosen as they correspond to the critical temperatures associated with the desorption of hydrogen from traps T1, T2 and T3 respectively as identified by Charitidou [2]. The heat treatment corresponding to desorption of hydrogen from T4 (at $\mathrm{T}=500{ }^{\circ} \mathrm{C}$ ) was not performed as this temperature is above the solution heat treatment temperature of AA $2024\left(495{ }^{\circ} \mathrm{C}\right)$. After each heat treatment, the sample was polished again down to $0.25 \mu \mathrm{m}$ with diamond paste to limit the influence of the surface oxide on the measured potential [15]. After $2 \mathrm{~h}$ at $130^{\circ} \mathrm{C}$, the lower potential zone is still visible (Fig. 7(b)), however the potential image has changed. Indeed in Fig. 7(e), $\Delta V_{\max }$ decreases from $550 \mathrm{mV}$ to $480 \mathrm{mV}$ while in Fig. 7(f) it decreases from $550 \mathrm{mV}$ to $380 \mathrm{mV}$. Moreover the width of the lower potential zone decreases after heat treatment at $130{ }^{\circ} \mathrm{C}$ down to $\sim 0.8 \mu \mathrm{m}$ (Fig. 7(f)) and $1 \mu \mathrm{m}$ (Fig. 7(e)). These results suggest some interstitial hydrogen desorption accelerated by the heat treatment at $130{ }^{\circ} \mathrm{C}$ as at this temperature only reversibly absorbed hydrogen is expected to desorb. After an additional heat treatment of $2 \mathrm{~h}$ at $200{ }^{\circ} \mathrm{C}$ and $410^{\circ} \mathrm{C}$, the potential maps have changed further (Fig. 7(c) and (d)). As seen on cross section 1 (Fig. 7(e)) (cross section 2 (Fig. 7(f)), $\Delta V_{\max }$ decreases further to $310 \mathrm{mV}(250 \mathrm{mV})$ and to $150 \mathrm{mV}$ (235 mV) after heat treatment at $200^{\circ} \mathrm{C}$ and $410{ }^{\circ} \mathrm{C}$ respectively. At these higher temperatures, hydrogen trapped at T2 and T3 is expected to desorb. Therefore the observed decrease in $\Delta V$ observed between the heat treatment at $130^{\circ} \mathrm{C}$ and the ones at $200^{\circ} \mathrm{C} / 410^{\circ} \mathrm{C}$ is associated with the desorption of irreversibly absorbed hydrogen. T2 is associated with hydrogen trapped at the semicoherent interface between the strengthening phases and the

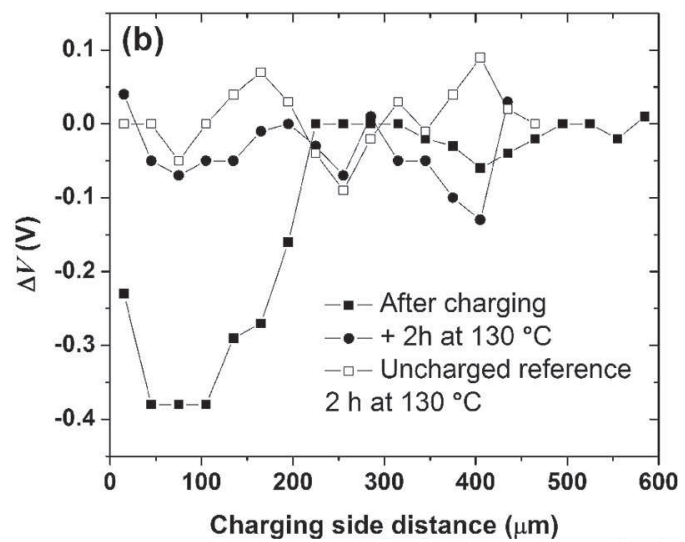

Fig. 6. Evolution of the SKPFM potential difference profiles $\Delta V=V_{\infty}-V_{x}$ after charging for $15 \mathrm{~h}$ ( $\boldsymbol{\square}$ ) and (a) after an additional exposure to air for $24 \mathrm{~h}$ ( $)$ and $48 \mathrm{~h}$ ( $\boldsymbol{\Delta}$ ); (b) after an additional heat treatment for $2 \mathrm{~h}$ at $130^{\circ} \mathrm{C}(\bullet)$. The data points $(\square)$ correspond to an uncharged reference heat treated for $2 \mathrm{~h}$ at $130{ }^{\circ} \mathrm{C}$. 

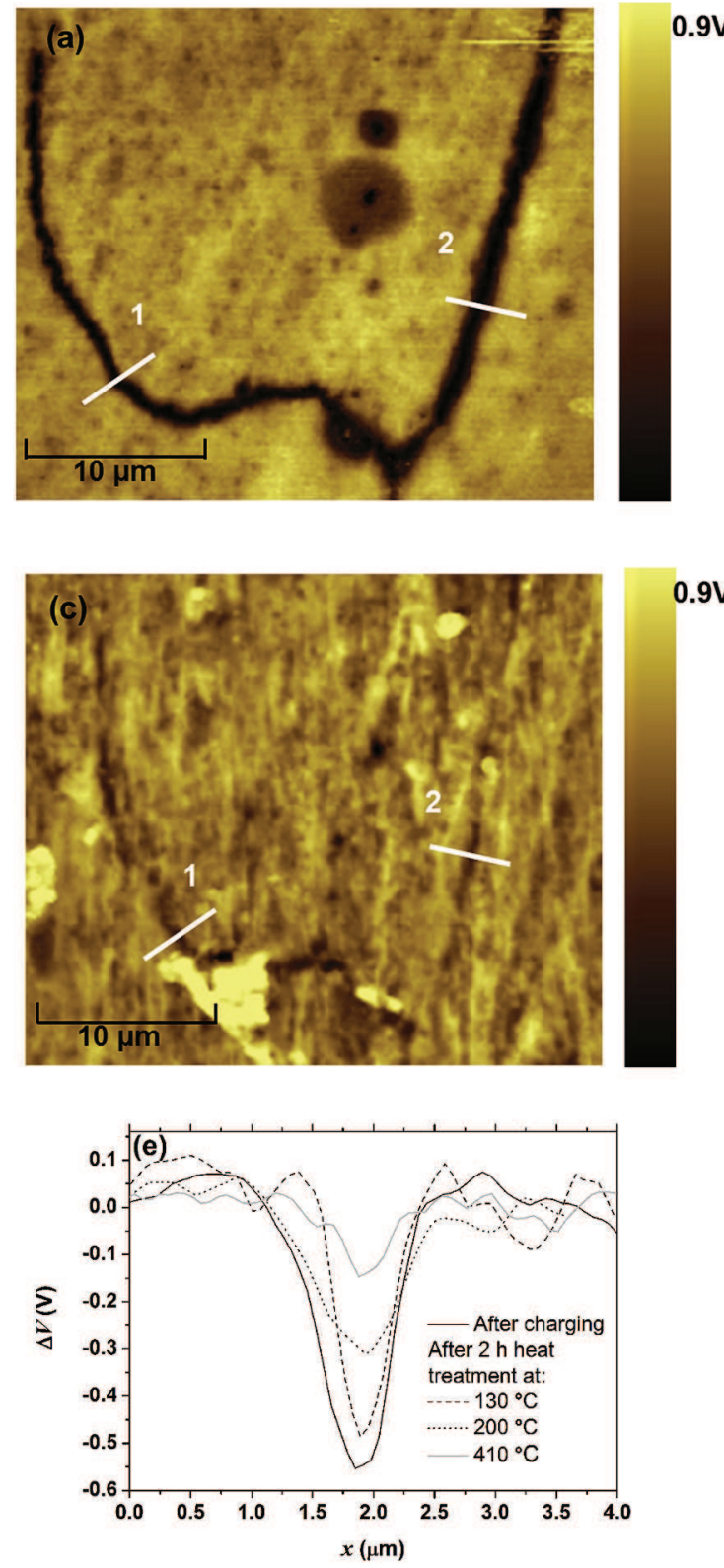
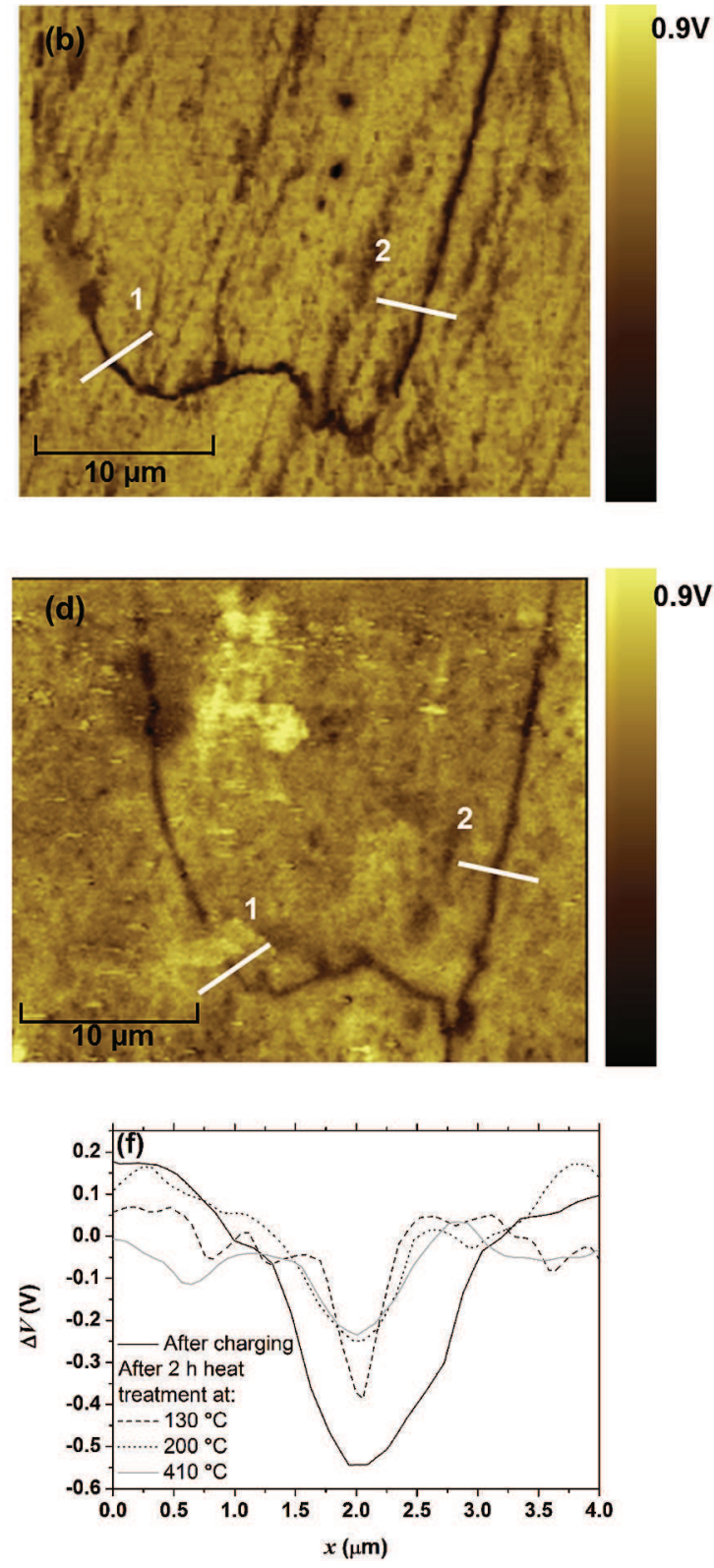

Fig. 7. SKPFM potential images of the same zone of an AA 2024 sample (a) after immersion for $24 \mathrm{~h}$ in $1 \mathrm{M} \mathrm{NaCl}$ and after additional heat treatment for $2 \mathrm{~h}$ at (b) $130{ }^{\circ} \mathrm{C}$, (c) $200{ }^{\circ} \mathrm{C}$ and (d) $410{ }^{\circ} \mathrm{C}$. (e) and (f) are the cross sections taken in zones 1 and 2 respectively.

matrix and/or with the incoherent interface between the dispersoids and the matrix and T3 with hydrogen trapped at dislocation $[1,13]$. A high density of dislocations is expected to be found near an intergranular corrosion defect [16] therefore it is logical that the potential evolution associated with hydrogen desorption from T3 is easily observed on the corroded sample while it was not observed on the H-charged samples (section 3.2). The fact that there is still a lower $\Delta V$ at the defect with respect to the matrix after a heat treatment at $410{ }^{\circ} \mathrm{C}$ might be due to hydrogen trapped at S-phase particles (T4). It could also be due to other corrosion products such as alumina or aluminum hydroxide or to a copper enrichment (or Cu-rich layer) at the grain boundaries due to corrosion [17-19]. Note that the quantitative variation of the potential map varies from cross section 1 and 2 suggesting heterogeneity in hydrogen content all along the corrosion defects and also heterogeneity of the corrosion defects itself concerning the density of dislocations and the presence of intermetallics for example.
Additionally after heat treatment at $200{ }^{\circ} \mathrm{C}$ and $410{ }^{\circ} \mathrm{C}$, a lower $\Delta V$ is observed over a zone wider than after the heat treatment at $130{ }^{\circ} \mathrm{C}$ but narrower than without heat treatment. This suggests diffusion and redistribution of hydrogen in the material induced by the heat treatment. Indeed, instead of desorbing out of the material, some hydrogen might get trapped at nearby defects with higher desorption temperatures.

\section{Conclusions}

An innovative method was developed to charge in hydrogen AA 2024 aluminum alloy at room temperature to ensure that there was no microstructural modifications of the aluminum alloy by artificial ageing. A SKPFM study combined with IGA measurements confirmed the insertion of hydrogen in the alloy. The desorption of hydrogen followed by SKPFM through the evolution of the potential gradients with time and temperature showed that SKPFM can be 
used to study hydrogen desorption kinetics. Additional measurements done at corrosion defects showed that SKPFM can detect $\mathrm{H}$ trapped both at reversible and irreversible sites. This study paves the way for a better understanding of the different trapping sites of hydrogen and their impact on the embrittlement of aluminum alloys.

\section{Acknowledgements}

The authors wish to thank Gregory Odemer for help with IGA measurements and for fruitful discussions. Manon Chloé Lafouresse wishes to thank Fabián Cádiz for help with the diffusion coefficient calculation. This work was supported by ANR-14-CE07-0027-01 M-SCOT: Multi Scale COrrosion Testing.

\section{References}

[1] H. Kamoutsi, G.N. Haidemenopoulos, V. Bontozoglou, S. Pantelakis, Corros. Sci 48 (2006) 1209-1224

[2] E. Charitidou, G. Papapolymerou, G.N. Haidemenopoulos, N. Hasiotis, V. Bontozoglou, Scr. Mater. 41 (12) (1999) 1327-1332.

[3] C. Senöz, S. Evers, M. Stratmann, M. Rohwerder, Electrochem. Comm. 13 (2011) 1542-1545.
[4] S. Evers, C. Senöz, M. Rohwerder, Sci. Technol. Adv. Mater. 14 (2013) 014201.

[5] M. Koyama, A. Bashir, M. Rohwerder, S.V. Merzlikin, E. Akiyama, K. Tsuzaki, D. Raabe, J. Electrochem. Soc. 162 (12) (2015) C638-C647.

[6] C. Larignon, J. Alexis, E. Andrieu, L. Lacroix, G. Odemer, C. Blanc, Scr. Mater. 68 (2013) 479-482.

[7] C. Larignon, J. Alexis, E. Andrieu, L. Lacroix, G. Odemer, C. Blanc, Electrochim. Acta 110 (2013) 484-490.

[8] C. Larignon, J. Alexis, E. Andrieu, C. Blanc, G. Odemer, J.-C. Salabura, J. Electrochem. Soc. 158 (9) (2011) C284-C295.

[9] H.K. Birnbaum, C.E. Buckley, F. Zeides, E. Sirois, P. Rozenak, S. Spooner, J.S. Lin, J. Alloys Comp. 253-254 (1997) 260-264.

[10] C.E. Buckley, H.K. Birnbaum, J. Alloys Compd. 330-332 (2002) 649-653.

[11] M. Nonnenmacher, M.P. O'Boyle, H.K. Wickramasinghe, Appl. Phys. Lett. 58 (1991) 2921-2923.

[12] R.W. Balluffi, S.M. Allen, W.C. Carter, Kinetics of Materials, second ed., John Wiley \& Sons, Hoboken, New Jersey, 1999.

[13] H. Kamoutsi, G.N. Haidemenopoulos, V. Bontozoglou, P.V. Petroyiannis, Sp.G. Pantelakis, Corros. Sci. 80 (2014) 139-142.

[14] M. C. Lafouresse, M-L. de Bonfils-Lahovary, C. Charvillat, L. Laffont, C. Blanc, Conference Proceedings NACE 2017, NACE Int., RIP 2017-9464.

[15] T.H. Muster, A.E. Hughes, J. Electrochem. Soc. 153 (11) (2006) B474-B485.

[16] C. Luo, X. Zhou, G.E. Thompson, A.E. Hughes, Corros. Sci. 61 (2012) 35-44.

[17] R.G. Buchheit, R.P. Grant, P.F. Hlava, B. McKenzie, G.L. Zender, J. Electrochem. Soc. 144 (8) (1997) 2621-2628.

[18] V. Guillaumin, G. Mandowski, Corros. Sci. 41 (1999) 421-438.

[19] M.-L. De Bonfils-Lahovary, L. Laffont, C. Blanc, Mater. Sci. Forum 877 (2017) $444-449$. 